\title{
Moderate Photoinhibition of Photosystem II Significantly Affects Linear Electron Flow in the Shade-Demanding Plant Panax notoginseng
}

\author{
Wei Huang ${ }^{1}$, Shi-Bao Zhang ${ }^{1 *}$ and Tao Liu ${ }^{2 *}$ \\ 1 Key Laboratory of Economic Plants and Biotechnology, Kunming Institute of Botany, Chinese Academy of Sciences, \\ Kunming, China, ${ }^{2}$ National Local Joint Engineering Research Center on Germplasm Utilization and Innovation of Chinese \\ Medicinal Materials in Southwest China, Yunnan Agricultural University, Kunming, China
}

OPEN ACCESS

Edited by:

William Walter Adams III, University of Colorado Boulder,

United States

Reviewed by:

David Kramer,

Michigan State University,

United States

Marian Brestic,

Slovak University of Agriculture

Slovakia

*Correspondence:

Shi-Bao Zhang

sbzhang@mail.kib.ac.cn

Tao Liu

52133490@qq.com

Specialty section:

This article was submitted to

Plant Abiotic Stress,

a section of the journal

Frontiers in Plant Science

Received: 04 September 2017

Accepted: 25 April 2018

Published: 15 May 2018

Citation:

Huang W, Zhang S-B and Liu T

(2018) Moderate Photoinhibition of Photosystem I/ Significantly Affects

Linear Electron Flow

in the Shade-Demanding Plant Panax notoginseng. Front. Plant Sci. 9:637.

doi: 10.3389/fpls.2018.00637
Although photoinhibition of photosystem II (PSII) frequently occurs under natural growing conditions, knowledge about the effect of moderate photoinhibition on linear electron flow (LEF) remains controversial. Furthermore, mechanisms underlying the decrease in LEF upon PSII photoinhibition are not well clarified. We examined how selective PSII photoinhibition influenced LEF in the attached leaves of shade-demanding plant Panax notoginseng. After leaves were exposed to a high level of light (2258 $\mu \mathrm{mol}$ photons $\mathrm{m}^{-2}$ $\left.\mathrm{s}^{-1}\right)$ for 30 and $60 \mathrm{~min}$, the maximum quantum yield of PSII $\left(F_{\mathrm{v}} / F_{\mathrm{m}}\right)$ decreased by 17 and $23 \%$, respectively, whereas the maximum photo-oxidizable P700 $\left(P_{\mathrm{m}}\right)$ remained stable. Therefore, this species displayed selective PSIl photodamage under strong illumination. After these treatments, LEF was significantly decreased under all light levels but acidification of the thylakoid lumen changed only slightly. Furthermore, the decrease in LEF under low light was positively correlated with the extent of PSIl photoinhibition. Thus, the decline in LEF was not caused by the enhancement of lumenal acidification, but was induced by a decrease in PSII activity. These results indicate that residual PSII activity is an important determinant of LEF in this shade-adapted species, and they provide new insight into how strong illumination affects the growth of shade-demanding plants.

Keywords: linear electron flow, lumenal acidification, photoinhibition, photosystem II, proton motive force

\section{INTRODUCTION}

During oxygenic photosynthesis in plants, leaves absorb light energy to drive photosynthetic electron flow in the chloroplasts. In linear electron flow (LEF), electrons from the splitting of water by the oxygen-evolving complex $(\mathrm{OEC})$ are transferred to $\mathrm{NADP}^{+}$, reducing $\mathrm{NADP}^{+}$to NADPH. This transfer is coupled to proton translocation across the thylakoid membrane, from stroma to lumen, which generates proton motive force $(p m f)$ to power the production of ATP via ATP synthase. Although light drives photosynthesis in higher plants, excessive irradiance can cause photoinhibition in the chloroplasts. Photosystem II (PSII) is very sensitive to high-light stress because D1 protein is decreased in the PSII reaction centers and OEC activity is subjected to 
photodamage (Aro et al., 1993a,b; Hakala et al., 2005; Ohnishi et al., 2005; Takahashi et al., 2009). This phenomenon, photoinhibition of PSII, can influence photosynthetic electron flow and overall plant growth (Kulheim et al., 2002; Murchie and Niyogi, 2011; Tikkanen et al., 2014).

Although the effect of PSII photoinhibition on LEF has been examined, the conclusions have been inconsistent from those studies. For example, a moderate decline in PSII activity does not result in a decrease in the light-saturated rates of $\mathrm{CO}_{2}$ assimilation for leaves from Salix sp. (Ogren and Sjostrom, 1990), or cause a reduction in the rate of oxygen evolution by Capsicum annuum leaves (Lee et al., 1999). Kornyeyev et al. (2006) have reported that moderate PSII inactivation $(<50 \%)$ is not associated with decreases in LEF and $\mathrm{CO}_{2}$ assimilation at light intensities above $150 \mu \mathrm{mol}$ photons $\mathrm{m}^{-2} \mathrm{~s}^{-1}$. In contrast, a correlation between PSII photoinhibition and the rate of electron transport has been observed with leaves of Chenopodium album in the presence of an inhibitor of PSII repair (Hikosaka et al., 2004), and also with leaves of Oryza sativa that are exposed to different periods of combined chillinglight stress (Hirotsu et al., 2005). Furthermore, Tikkanen et al. (2014) have stated that electron transfer from PSII to PSI is depressed upon moderate PSII photoinhibition. Therefore, these contrasting results underscore the need for further research that can clearly elucidate the effect of selective PSII photoinhibition on LEF.

In previous studies that explored how PSII photoinhibition influences LEF, some factors of photosynthesis have been concomitant, such as the closure of stomata in response to low temperatures (Hirotsu et al., 2005), chilling-induced PSI photoinhibition (Kornyeyev et al., 2006), PSI photoinhibition due to intense illumination (Tikkanen et al., 2014), and measurements being made with detached leaves (Hikosaka et al., 2004; Kornyeyev et al., 2006; Tikkanen et al., 2014). Under lowtemperature stress, a longer treatment period means that PSII photoinhibition will be more severe and accompanied by a larger decrease in stomatal conductance (Hirotsu et al., 2005), thereby affecting the rate of the Calvin-Benson cycle and, thus, LEF. Kornyeyev et al. (2006) have conducted experiments with stillattached Arabidopsis thaliana leaves that are initially exposed for $2 \mathrm{~h}$ to $5^{\circ} \mathrm{C}$ and intense light $\left(2000 \mu \mathrm{mol}\right.$ photons $\left.\mathrm{m}^{-2} \mathrm{~s}^{-1}\right)$. They have found that this combined chilling-light treatment leads to a $45 \%$ decrease in PSI activity. Likewise, Tikkanen et al. (2014) have shown that a high-light treatment causes significant PSI photoinhibition in pgr5-plants of $A$. thaliana. Because PSI photoinhibition can severely affect the rate of LEF (Zivcak et al., 2015), the conclusions of Kornyeyev et al. (2006) and Tikkanen et al. (2014) are interfered by PSI photoinhibition. Some research has utilized detached, rather than attached, leaves for making photosynthetic measurements (Hikosaka et al., 2004; Kornyeyev et al., 2006; Tikkanen et al., 2014). This decision has cast doubt on how stomatal conductance might be influenced in those experiments. Therefore, it is difficult to confirm those previous results due to the shortcomings associated with the investigations.

Although PSII photoinhibition diminishes LEF under low light (Kornyeyev et al., 2006; Tikkanen et al., 2014), the responsible mechanism is unclear. Previous reports have indicated that moderate PSII photoinhibition can lead to a significant decrease in LEF (Tikkanen et al., 2014) and overacidification of the thylakoid lumen is associated with downregulation of LEF (Livingston et al., 2010). Specifically, it is unknown whether the decrease in LEF upon moderate PSII photoinhibition is caused by a decline in PSII activity or by the enhancement of lumenal acidification. When PSII is photodamaged, cyclic electron flow (CEF) is significantly stimulated when plants are allowed to recover under low light (Huang et al., 2010, 2016a), which might make the thylakoid lumen more acidic. Lumenal acidification plays a critical role in controlling electron transfer from PSII at the Cyt $b_{6} / f$ (Nishio and Whitmarsh, 1993; Hope et al., 1994; Takizawa et al., 2007). In hcef1, an A. thaliana mutant with high CEF, increased NDHdependent CEF leads to over-acidification of the thylakoid lumen, thus restricting LEF (Livingston et al., 2010). Under drought stress without PSII photoinhibition, the stimulation of CEF increases the lumenal acidification, enhancing NPQ and lowering LEF in the resurrection plant Paraboea rufescens (Huang et al., 2012). The induction of NPQ under high light does not strongly decrease LEF, as shown by the similar light-intensity dependence of photosynthesis in WT, $n p q 1$, and $n p q 4$ (Takahashi et al., 2009; Johnson and Ruban, 2010). Therefore, a change in CEF stimulation may affect the operation of LEF. However, it is unclear whether the depression of LEF upon PSII photoinhibition is caused by the loss of PSII activity or the enhancement of lumenal acidification.

In a previous investigation, we observed that shade-grown Panax notoginseng exhibited selective PSII photoinhibition after short-term treatment under high light. Therefore, we used plants of this species here to examine the effect of selective PSII photoinhibition on LEF. In this study, we focused on the mechanism underlying the decrease in LEF, and we investigated the relationship between low-light LEF and PSII activity. Regardless of light levels, moderate PSII photoinhibition significantly affected LEF. Furthermore, the reduction in LEF was independent of $p m f$ but was significantly related to the decrease in PSII activity.

\section{MATERIALS AND METHODS}

\section{Plant Materials}

Two-year-old plants of the shade-adapted $P$. notoginseng (Burkill) F. H. Chen ex C. Chow and W. G. Huang were grown indoors under $10 \%$ sunlight, and were watered and fertilized normally to avoid the onset of drought or nutrient stresses. Photosynthetic parameters were evaluated with 8-week-old fully expanded leaves.

\section{Chlorophyll Fluorescence and P700 Measurements}

Both PSI and PSII parameters were monitored at $25^{\circ} \mathrm{C}$ by simultaneously recording chlorophyll fluorescence and P700 redox state with a Dual PAM-100 measuring system (Heinz Walz, Effeltrich, Germany). After light-adaptation at $611 \mu \mathrm{mol}$ photons $\mathrm{m}^{-2} \mathrm{~s}^{-1}$ for $15 \mathrm{~min}$ to fully activate photosynthesis, light-adapted 
photosynthetic parameters were evaluated after exposure to each light intensity $(923,611,421,272,172,132,94$, and $59 \mu \mathrm{mol}$ photons $\mathrm{m}^{-2} \mathrm{~s}^{-1}$ ) for $2 \mathrm{~min}$.

The chlorophyll fluorescence parameters were calculated as follows: $F_{\mathrm{v}} / F_{\mathrm{m}}=\left(F_{\mathrm{m}}-F_{\mathrm{o}}\right) / F_{\mathrm{m}} ; Y(\mathrm{II})=\left(F_{\mathrm{m}}{ }^{\prime}-F_{\mathrm{s}}\right) / F_{\mathrm{m}}$ ' (Genty et al., 1989); $\mathrm{NPQ}=\left(F_{\mathrm{m}}-F_{\mathrm{m}}{ }^{\prime}\right) / F_{\mathrm{m}}$ '; $\mathrm{qL}=\left(F_{\mathrm{m}}{ }^{\prime}-F_{\mathrm{s}}\right) /\left(F_{\mathrm{m}}{ }^{\prime}-F_{\mathrm{o}}{ }^{\prime}\right) \times F_{\mathrm{o}}{ }^{\prime} / F_{\mathrm{s}} ; F_{\mathrm{o}}{ }^{\prime}=F_{\mathrm{o}} /\left(F_{\mathrm{v}} / F_{\mathrm{m}}+F_{\mathrm{o}} / F_{\mathrm{m}}{ }^{\prime}\right)$ (Oxborough and Baker, 1997). $F_{\mathrm{o}}$ and $F_{\mathrm{m}}$ are the minimum and maximum fluorescence after dark-adaptation, respectively; $F_{\mathrm{o}}$ ' and $F_{\mathrm{m}}$ ' represent the minimum and maximum fluorescence after light adaptation, respectively; and $F_{\mathrm{s}}$ is the light-adapted steady-state fluorescence. Both $F_{\mathrm{o}}$ and $F_{\mathrm{m}}$ were determined after the plants were dark-adapted for $30 \mathrm{~min}$ before and after the high-light treatment was applied.

The PSI photosynthetic parameters were measured with a Dual PAM-100, based on the P700 signal (i.e., the difference in intensities of 830 and $875 \mathrm{~nm}$ pulse-modulated measuring light reaching the photodetector) (Klughammer and Schreiber, 2008). The $\mathrm{P} 700^{+}$signal $(P)$ may vary between a minimum (P700 fully reduced) and maximum (P700 fully oxidized) level. We determined the maximum level $\left(P_{\mathrm{m}}\right)$ by applying a saturating pulse $\left(600 \mathrm{~ms}, 10,000 \mu \mathrm{mol}\right.$ photons $\mathrm{m}^{-2} \mathrm{~s}^{-1}$ ) after preillumination with far-red light, and then used $P_{\mathrm{m}}$ to estimate PSI activity (Huang et al., 2010; Brestic et al., 2015; Yamori et al., 2016; Takagi et al., 2017). The $P_{\mathrm{m}}$ ' was determined similar to $P_{\mathrm{m}}$ but with actinic light instead of far-red light. The following calculations were made: quantum yield of PSI, $Y(\mathrm{I})=\left(P_{\mathrm{m}}{ }^{\prime}-P\right) / P_{\mathrm{m}}$; the $\mathrm{P} 700$ oxidation ratio for a given actinic light, $Y(\mathrm{ND})=P / P_{\mathrm{m}}$; and the fraction of $\mathrm{P} 700$ that could not be oxidized by a saturating pulse in proportion to the overall P700, $Y(\mathrm{NA})=\left(P_{\mathrm{m}}-P_{\mathrm{m}}{ }^{\prime}\right) / P_{\mathrm{m}}$.

Photosynthetic electron flows through PSI and PSII were calculated as: ETRII $=Y(\mathrm{II}) \times \mathrm{PPFD} \times 0.84 \times 0.5$ and $\mathrm{ETRI}=Y(\mathrm{I}) \times \mathrm{PPFD} \times 0.85 \times 0.5$, where 0.5 was assumed to be the proportion of absorbed light reaching PSI or PSII, and 0.85 was assumed to be the absorbance (i.e., the fraction of incident light absorbed by the leaves). The value for CEF was estimated as ETRI - ETRII (Huang et al., 2012).

\section{Electrochromic Shift (ECS) Analysis}

The ECS signal was monitored as the change in absorbance at $515 \mathrm{~nm}$, which was measured with a Dual-PAM-100 that was equipped with a P515/535 emitter-detector module (Heinz Walz). After illumination at $54 \mu \mathrm{mol}$ photons $\mathrm{m}^{-2} \mathrm{~s}^{-1}$ for $20 \mathrm{~min}$, ECS decay was measured by switching off the actinic light for $30 \mathrm{~s}$. The analysis of ECS dark interval relaxation kinetics was performed according to the methods of Sacksteder et al. (2001) and Takizawa et al. (2008). Total pmf was estimated from the total amplitude of the rapid decay of the ECS signal during a 300-ms dark interval. Slow relaxation of the ECS signal was used to recognize the proton gradient across the thylakoid membrane $(\Delta \mathrm{pH})$. The time constant for first-order ECS relaxation $\left(\tau_{\mathrm{ECS}}\right)$ is inversely proportional to the proton conductivity $\left(g_{\mathrm{H}}^{+}\right)$of the thylakoid membrane through ATP synthase (Sacksteder and Kramer, 2000; Cruz et al., 2005). This allowed us to estimate $g_{\mathrm{H}}{ }^{+}$as the inverse of the decay time constant $\left[1 / \tau_{\mathrm{ECS}}\right]$. The relative light-driven proton flux
$\left(v_{\mathrm{H}+}\right)$ was obtained by using the initial slope of the ECS relaxation.

\section{Photoinhibitory Treatments}

After dark-adaptation for $30 \mathrm{~min}, F_{\mathrm{v}} / F_{\mathrm{m}}$ and $P_{\mathrm{m}}$ were measured for intact leaves, which were then light-adapted at $611 \mu \mathrm{mol}$ photons $\mathrm{m}^{-2} \mathrm{~s}^{-1}$ for $15 \mathrm{~min}$. Afterward, light response curves were measured as described above before the actinic light was changed to $2258 \mu \mathrm{mol}$ photons $\mathrm{m}^{-2} \mathrm{~s}^{-1}$. After exposure to this more intense illumination for 30 or $60 \mathrm{~min}$, the light response curves were measured immediately. Finally, $F_{\mathrm{v}} / F_{\mathrm{m}}$ and $P_{\mathrm{m}}$ were evaluated after the leaves were dark-adapted for $30 \mathrm{~min}$. To evaluate the ECS signal, we first exposed dark-adapted leaves to $59 \mu \mathrm{mol}$ photons $\mathrm{m}^{-2} \mathrm{~s}^{-1}$ for $20 \mathrm{~min}$ to obtain the ECS parameters in unstressed leaves. Afterward, the same leaves were treated at $2258 \mu \mathrm{mol}$ photons $\mathrm{m}^{-2} \mathrm{~s}^{-1}$ for $30 \mathrm{~min}$. The ECS parameters were determined after adaptation at $59 \mu \mathrm{mol}$ photons $\mathrm{m}^{-2} \mathrm{~s}^{-1}$ for $20 \mathrm{~min}$. The level of actinic light was then changed to $2258 \mu \mathrm{mol}$ photons $\mathrm{m}^{-2} \mathrm{~s}^{-1}$ or a period of $30 \mathrm{~min}$ before ECS parameters were again measured after the leaves were exposed to $59 \mu \mathrm{mol}$ photons $\mathrm{m}^{-2} \mathrm{~s}^{-1}$ for $20 \mathrm{~min}$.

\section{Statistical Analysis}

All of the results were presented as mean values from five independent experiments. Independent $T$-test were used at a significance level of $\alpha=0.05$ (before/after) to determine whether the light treatments had a significant effect on photosynthetic parameters.

\section{RESULTS}

\section{Responses of PSI and PSII Activities to High Light}

To induce PSII photoinhibition, we exposed intact leaves of $P$. notoginseng to intense illumination, i.e., $2258 \mu \mathrm{mol}$ photons $\mathrm{m}^{-2} \mathrm{~s}^{-1}$. Under such treatment, the value for ETRII gradually decreased, measuring $19.5 \mu \mathrm{mol}$ electrons $\mathrm{m}^{-2} \mathrm{~s}^{-1}$ after $6 \mathrm{~min}$ and further declining to $14 \mu \mathrm{mol}$ electrons $\mathrm{m}^{-2} \mathrm{~s}^{-1}$ after $60 \mathrm{~min}$ (Figure 1A). During that period, $F_{\mathrm{v}} / F_{\mathrm{m}}$ decreased by $17 \%$ after $30 \mathrm{~min}$ and by $23 \%$ after $60 \mathrm{~min}$ (Figure 1B), while $P_{\mathrm{m}}$ was reduced by only 3 and 4\%, respectively (Figure 1B). These results demonstrated that this shade-adapted species $P$. notoginseng shows selective PSII photoinhibition under high-light stress.

\section{Effects of High-Light Treatments on Photosynthetic Electron Flow}

Light response curves indicated that the value for $Y(\mathrm{I})$ decreased slightly after $30 \mathrm{~min}$ of high-light treatment (Figure 2A). Meanwhile, the values for $Y(\mathrm{ND})$ under light intensities below $132 \mu \mathrm{mol}$ photons $\mathrm{m}^{-2} \mathrm{~s}^{-1}$ increased significantly (Figure $2 \mathrm{~B}$ ), and the values for $Y(\mathrm{NA})$ under $59 \mu \mathrm{mol}$ photons $\mathrm{m}^{-2}$ $\mathrm{s}^{-1}$ largely decreased (Figure 2C). After high-light treatment for $60 \mathrm{~min}, Y(\mathrm{I})$ decreased significantly under all light intensities (Figure 2D), $Y(\mathrm{ND})$ increased significantly under light intensities below $421 \mu \mathrm{mol}$ photons $\mathrm{m}^{-2} \mathrm{~s}^{-1}$ (Figure 2E), 

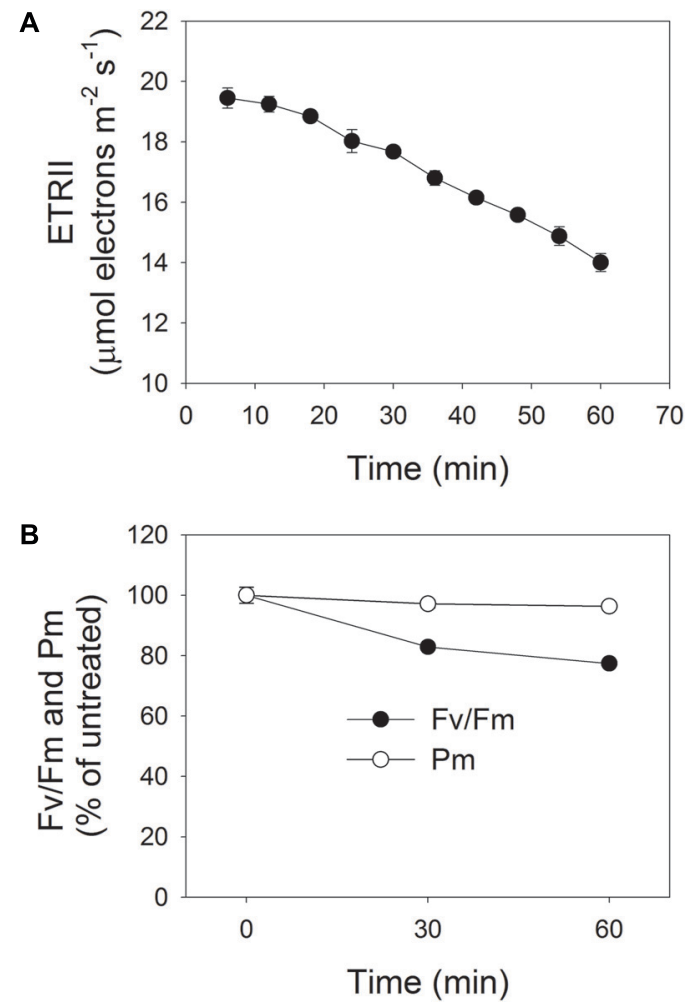

FIGURE 1 | (A) Change in rate of electron flow through PSII (ETRII) during exposure to high light $\left(2258 \mu \mathrm{mol}\right.$ photons $\left.\mathrm{m}^{-2} \mathrm{~s}^{-1}\right)$ for $60 \mathrm{~min}$. After $25 \mathrm{~min}$ of light-adaptation at $611 \mu \mathrm{mol}$ photons $\mathrm{m}^{-2} \mathrm{~s}^{-1}$ and measurement of light response curve (at Minute 16), actinic light intensity was changed to 2258 $\mu \mathrm{mol}$ photons $\mathrm{m}^{-2} \mathrm{~s}^{-1}$ and PSII parameters were recorded during next 60 min. (B) Changes in PSI and PSIl activities after exposure to $2258 \mu \mathrm{mol}$ photons $\mathrm{m}^{-2} \mathrm{~s}^{-1}$ for 30 and $60 \mathrm{~min}$. Maximum quantum yield of $\mathrm{PSII}\left(F_{\mathrm{v}} / F_{\mathrm{m}}\right)$ represents PSII activity; maximum photo-oxidizable P700 $\left(P_{m}\right)$ represents PSI activity. Pre-treatment value for $F_{\mathrm{v}} / F_{\mathrm{m}}$ was 0.804 . Values are means $\pm \mathrm{SE}$ $(n=5)$.

and $Y(\mathrm{NA})$ decreased significantly under light intensities below $132 \mu \mathrm{mol}$ photons $\mathrm{m}^{-2} \mathrm{~s}^{-1}$ (Figure 2F). This showed that the high-light treatment significantly affected the PSI redox state under low light.

After high-light treatment for $30 \mathrm{~min}$ or $60 \mathrm{~min}, Y(\mathrm{II})$ decreased significantly under all light intensities (Figures 3A,D), and the capacity of NPQ largely declined (Figures 3B,E). We found it interesting that the redox state of $Q_{A}(q L)$ was only slightly altered by these treatments (Figures 3C,F). This suggested that the ability of the leaves to utilize the product of LEF was hardly affected by exposure to intense illumination.

After high-light treatment for $30 \mathrm{~min}$, the values of ETRI under all light intensities decreased slightly (Figure 4A), while ETRII values under all light conditions decreased significantly (Figure 4B). By comparison, after $60 \mathrm{~min}$ of high-light treatment, both ETRI and ETRII decreased significantly regardless of intensity (Figures 4E,F). Although the capacity of LEF was depressed by these treatments (Figures $4 \mathbf{B}, \mathbf{F}$ ), the maximum value for CEF was only slightly changed (Figures 4C,G).
Furthermore, CEF was stimulated significantly under low light intensities, i.e., 59 and $94 \mu \mathrm{mol}$ photons $\mathrm{m}^{-2} \mathrm{~s}^{-1}$ (Figures 4C,G). Prior to high-light treatment, CEF was hardly activated at $59 \mu \mathrm{mol}$ photons $\mathrm{m}^{-2} \mathrm{~s}^{-1}$. However, after high-light treatment for 30 to $60 \mathrm{~min}$, CEF was significantly stimulated at that low level of light. Therefore, due to the decrease in ETRII, the ETRI/ETRII ratio increased significantly after high-light treatments, regardless of light intensity (Figures 4D,H).

\section{Effects of High-Light Treatments on Proton Motive Force}

To examine whether the depression of LEF induced by highlight treatments is caused by enhanced lumenal acidification, we determined the ECS signal at $59 \mu \mathrm{mol}$ photons $\mathrm{m}^{-2} \mathrm{~s}^{-1}$ before and after the treatments were applied. We found it interesting that total $p m f$ decreased significantly after high-light treatments (Figure 5A) while $\Delta \mathrm{pH}$ was not significantly changed (Figure 5B). The proton conductivity $\left(g_{\mathrm{H}}^{+}\right)$of the thylakoid membrane was slightly altered before and after (Figure 5C), which suggested that the high-light treatments hardly affected the activity of chloroplastic ATP synthase under low light. These results indicated that the decline in LEF under low light could not be explained by the change in lumenal acidification.

Figure 6 shows the relationship between relative light-driven proton flux $\left(v_{\mathrm{H}+}\right)$ and ETRII. This plot was developed to test for contributions from CEF because $v_{\mathrm{H}}$ should reflect the proton flux generated by the operation of both CEF and LEF while the chlorophyll fluorescence-derived LEF parameter only measures electron transfer from PSII. After high-light treatments, leaves showed higher $v_{\mathrm{H}}+$ as a function of LEF, suggesting that CEF was stimulated under low light upon PSII photoinhibition.

\section{Effects of PSII Photoinhibition on LEF and P700 Oxidation Ratio at Low Light}

The effect of PSII photoinhibition on LEF under low light was further examined by pooling the data for $F_{\mathrm{V}} / F_{\mathrm{m}}$ and the decrease in ETRII at $59 \mu \mathrm{mol}$ photons $\mathrm{m}^{-2} \mathrm{~s}^{-1}\left(\right.$ ETRII $\left._{59}\right)$ after high-light treatments. Here, the value for $F_{\mathrm{v}} / F_{\mathrm{m}}$ was negatively correlated with the decrease in ETRII $_{59}$ (Figure 7A), suggesting that residual PSII activity significantly affected the operation of LEF. That is, the number of PSII complexes was not sufficient to sustain maximum LEF under low light. We also examined the relationship between PSII photoinhibition and $Y(\mathrm{ND})$ values at $59 \mu \mathrm{mol}$ photons $\mathrm{m}^{-2} \mathrm{~s}^{-1}\left[Y(\mathrm{ND})_{59}\right]$. Our results indicated that $F_{\mathrm{v}} / F_{\mathrm{m}}$ was negatively correlated with $Y(\mathrm{ND})_{59}$ (Figure 7B). Therefore, the extent of PSII photoinhibition significantly increased the P700 oxidation ratio under low light (Figure 7B).

\section{DISCUSSION}

\section{Different Responses of PSI and PSII to High-Light Treatments}

Under strong illumination, excess absorbed light energy can cause PSII photoinhibition (Powles, 1984; Barber and Andersson, 1992; Aro et al., 1993a,b; Takahashi et al., 2009). High-light 

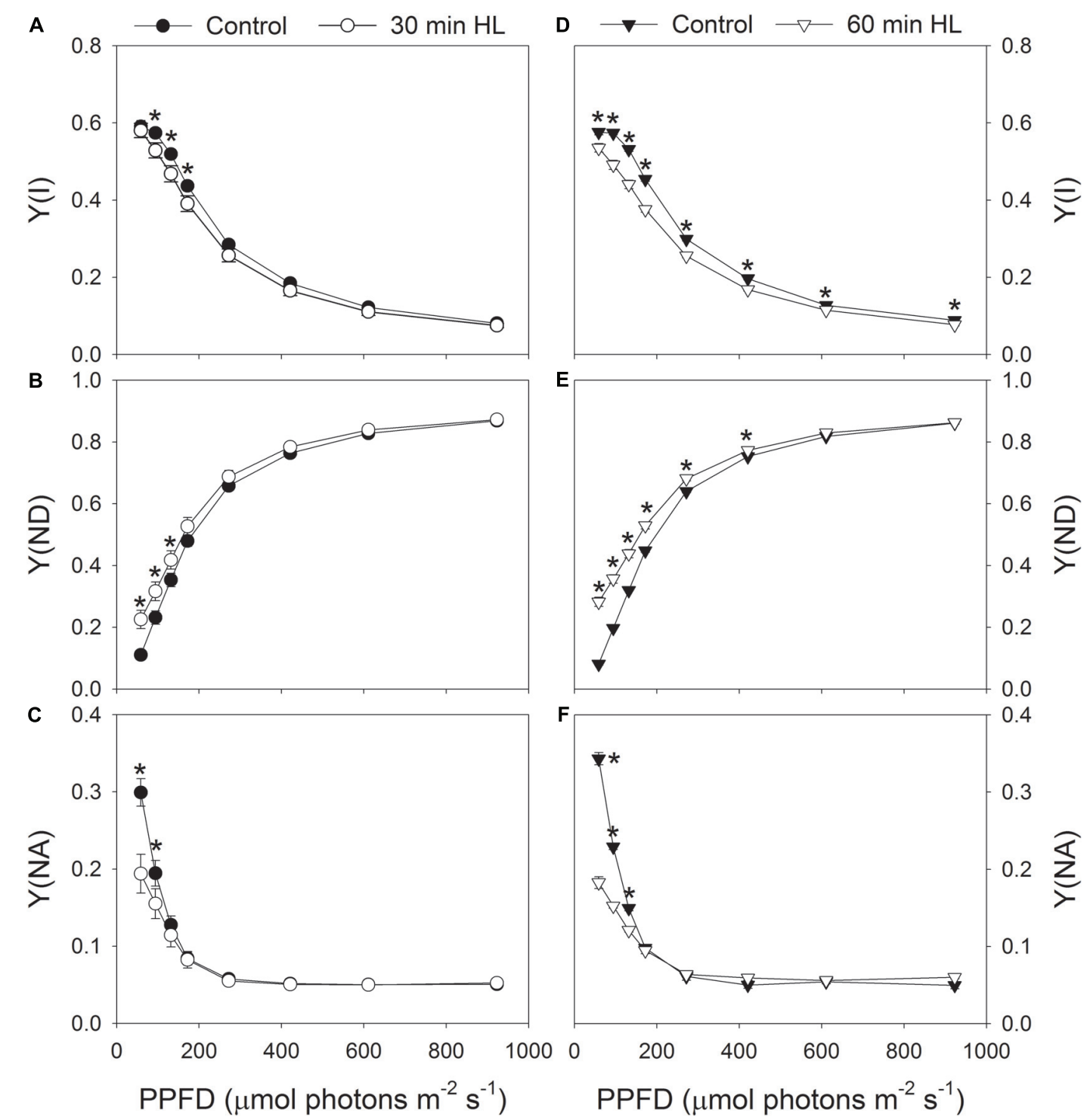

FIGURE 2 | Effects of high-light treatments on light response changes in $Y(I)(\mathbf{A}, \mathbf{D}), Y(N D)$ (B,E), and $Y(N A)$ (C,F). $Y(I)$, quantum yield of PSI photochemical quenching; $Y(N D)$, quantum yield of PSI non-photochemical energy dissipation due to donor-side limitation; $Y(N A)$, quantum yield of PSI non-photochemical energy due to acceptor-side limitation. Values are means \pm SE $(n=5)$. Asterisks indicate significant differences after high-light treatments.

treatment induces a large decrease in PSII activity in the shade leaves of pioneer and late-succession tree species as well as other plants (Aro et al., 1993b; Kitao et al., 2000; Barth et al., 2001; Krause et al., 2004), while PSI activity is usually unaffected (Barth et al., 2001). However, PSI activity can also be sensitive to high-light stress in some shade-adapted tree species such as Psychotria rubra, Psychotria henryi, and Nephrolepis falciformis (Huang et al., 2015, 2016c,d, 2017, 2018). By comparison, we found that PSI activity was not susceptible to such stress in $P$. notoginseng, which indicated that this response is speciesdependent and cannot be generalized. Because the response of photosynthesis to environmental stresses may be associated with the origin of a plant (Brestic et al., 2012), future studies should focus on a wide range of evolutionarily divergent species if we are to obtain a more comprehensive understanding of how PSI activity responds to high-light stress in shade-demanding species.

Photoinhibition occurs only under conditions in which the rate of photodamage exceeds the rate of its repair (Allakhverdiev et al., 2003, 2005, 2007, 2008; Allakhverdiev and Murata, 2004). After its reaction center is photodamaged, PSII can be rapidly and effectively repaired by replacing the damaged PSII proteins with newly synthesized proteins, primarily D1 protein (Allakhverdiev and Murata, 2004; Takahashi et al., 2009; Murata et al., 2012). The photorespiratory pathway and the Calvin-Benson cycle are important for protecting PSII against photoinhibition (Brestic et al., 1995; Lin et al., 2000; Murata et al., 2007; Takahashi et al., 2007). For the shade-adapted $P$. notoginseng, the relatively low capacity of ETRII indicates that this species has less capacity 

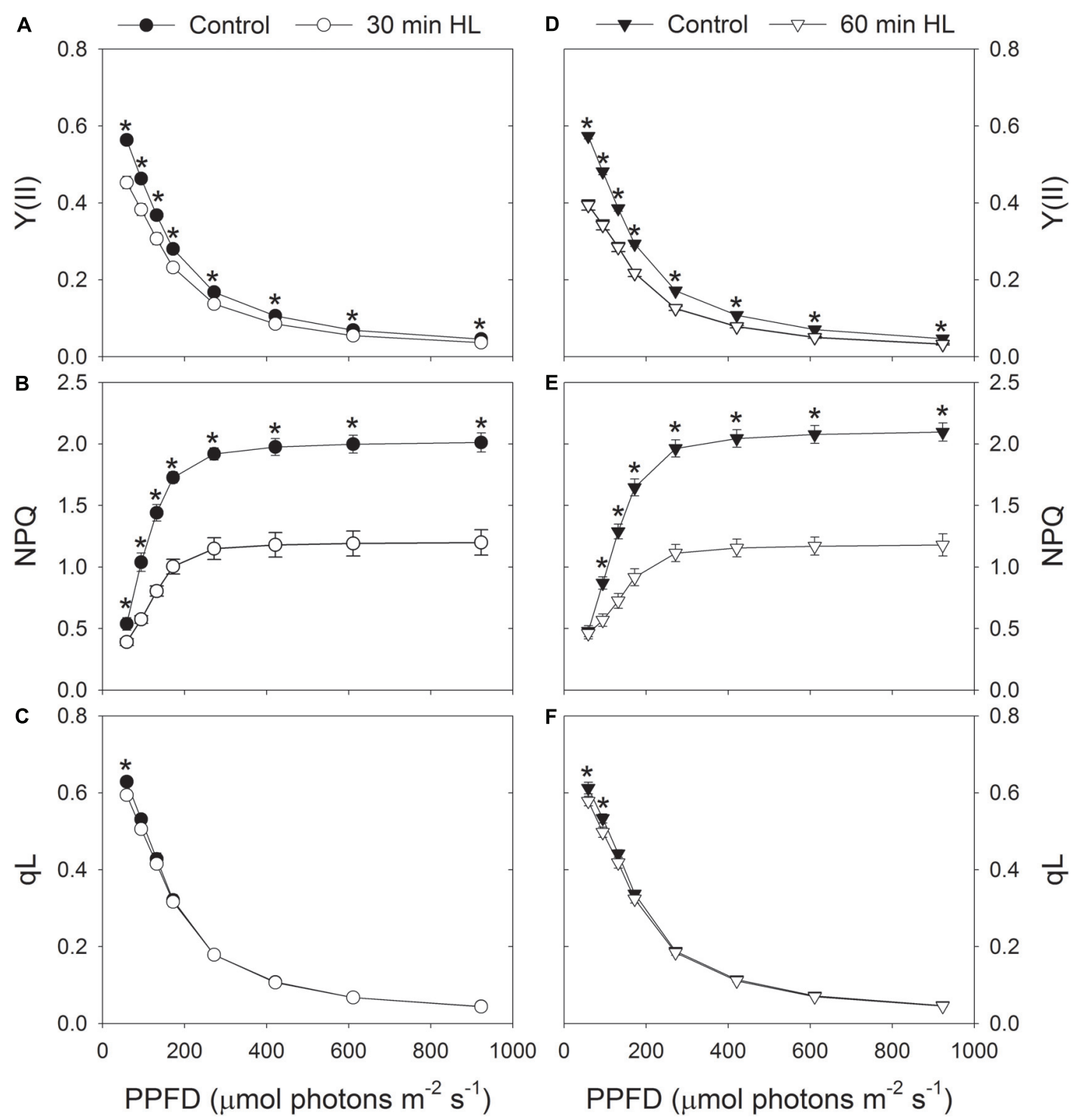

FIGURE 3 | Effects of high-light treatments on light response changes in $Y($ II) $\mathbf{( A , D ) , ~ N P Q ~ ( B , E ) , ~ a n d ~ q L ~ ( C , F ) . ~ Y ( I I ) , ~ e f f e c t i v e ~ q u a n t u m ~ y i e l d ~ o f ~ P S I I ~ p h o t o c h e m i s t r y ; ~}$ $\mathrm{NPQ}$, non-photochemical quenching in PSIl; qL, fraction of open PSIl reaction centers. Calculations of NPQ and qL were based on values of $F_{0}$ and $F_{m}$ measured before and after treatment. Values are means \pm SE $(n=5)$. Asterisks indicate significant differences after high-light treatments.

for the photorespiratory pathway and the Calvin-Benson cycle. As a result, under high-light stress, excess absorbed light energy induces the production of a large amount of reactive oxygen species that inhibit the fast recovery of its photodamaged PSII complexes (Nishiyama et al., 2001, 2004, 2006).

\section{PSII Photoinhibition Affects LEF Under All Light Intensities}

Our results confirmed that LEF gradually decreased during exposure to a light intensity of $2258 \mu \mathrm{mol}$ photons $\mathrm{m}^{-2}$ $\mathrm{s}^{-1}$. Furthermore, after exposure to this high level for 30 or $60 \mathrm{~min}$, the rates of ETRII under all tested intensities decreased significantly. These results suggested that moderate
PSII photoinhibition is accompanied by the depression of LEF under all light intensities in $P$. notoginseng, findings that are similar to those reported by Tikkanen et al. (2014). Although a decline in LEF upon PSII photoinhibition has been described by other researchers (Hikosaka et al., 2004; Hirotsu et al., 2005; Kornyeyev et al., 2006; Tikkanen et al., 2014), it is unclear whether that phenomenon is caused by a decrease in PSII activity or because lumenal acidification is enhanced. Electron transfer from PSII to PSI can be controlled by the Cyt $b_{6} / f$ complex, based on $\Delta \mathrm{pH}$ (Nishio and Whitmarsh, 1993; Hope et al., 1994; Suorsa et al., 2012, 2016; Shikanai, 2014, 2016; Tikkanen and Aro, 2014). Over-acidification of the thylakoid lumen down-regulates LEF, thereby restricting overall plant growth (Livingston et al., 2010). Here, we found that $\Delta \mathrm{pH}$ did not increase after the high-light 


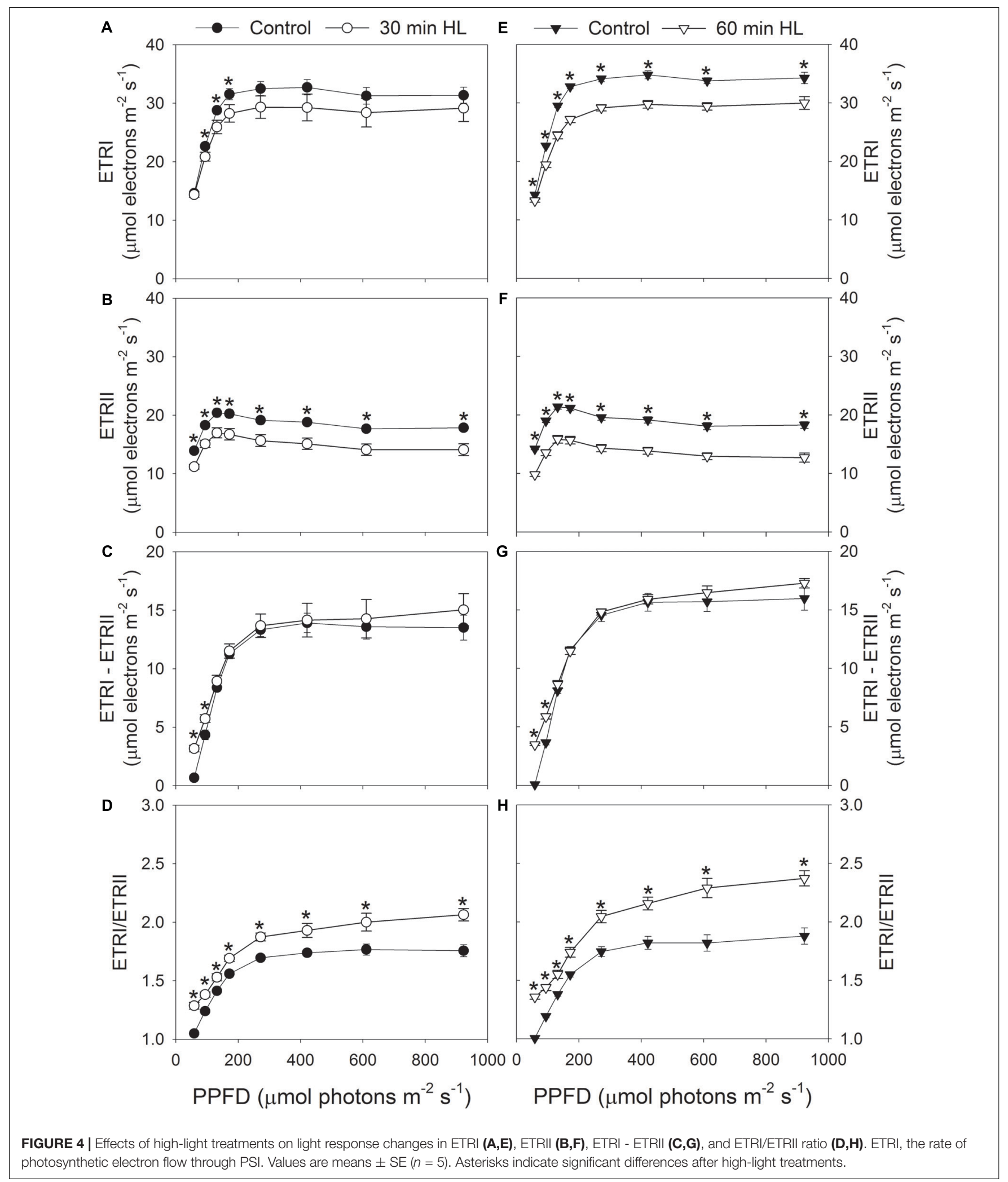

treatments. Therefore, we cannot conclude that the reduction in LEF is associated with a change in the extent of lumenal acidification. Furthermore, the activity of thylakoid ATP synthase and $\mathrm{qL}$ were only slightly altered after high-light treatments. These findings strongly demonstrated that this depression of LEF was mainly caused by a decrease in PSII activity. 

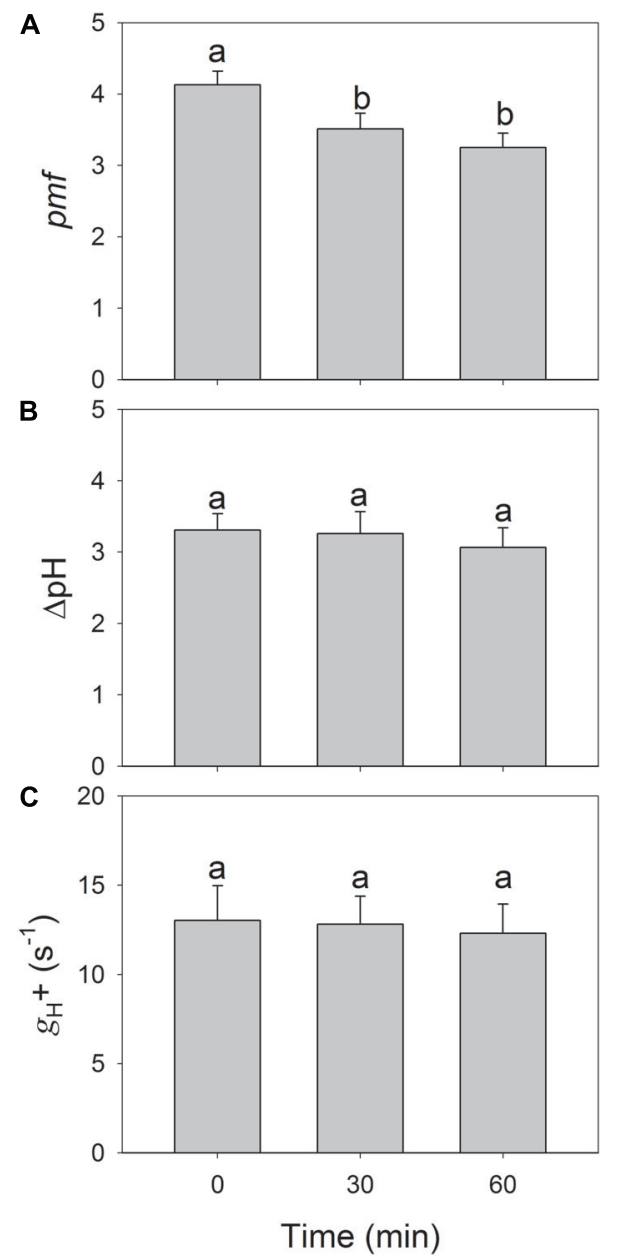

FIGURE $\mathbf{5}$ | Changes in total proton motive force $(p m f)$ (A), proton gradient across the thylakoid membrane $(\Delta \mathrm{pH})(\mathbf{B})$, and the proton conductivity of the thylakoid membrane $\left(g_{H^{+}}\right)$(C) after exposure to $2258 \mu \mathrm{mol}$ photons $\mathrm{m}^{-2} \mathrm{~s}^{-1}$ for 30 and $60 \mathrm{~min}$. All parameters were measured after adaptation at $54 \mu \mathrm{mol}$ photons $\mathrm{m}^{-2} \mathrm{~s}^{-1}$ for $20 \mathrm{~min}$. Values are means $\pm \mathrm{SE}(n=5)$. Different letters indicate a significant change after high-light treatments.

In studies that utilized the detached leaves of A. thaliana, results have been inconsistent about the influence of moderate PSII photoinhibition on LEF. For example, Kornyeyev et al. (2006) have shown that photoinhibition of less than $50 \%$ leads to a decrease in LEF at light intensities below $150 \mu \mathrm{mol}$ photons $\mathrm{m}^{-2} \mathrm{~s}^{-1}$ but is not associated with LEF reductions at intensities above $150 \mu \mathrm{mol}$ photons $\mathrm{m}^{-2} \mathrm{~s}^{-1}$. In contrast, Tikkanen et al. (2014) have reported that electron flow from PSII under high light is markedly diminished, i.e., by approximately $40 \%$. Those studies also examined PSI photoinhibition due to either chilling treatment (Kornyeyev et al., 2006) or disruption of the PGR5CEF pathway (Tikkanen et al., 2014). Because PSI activity plays important roles in photosynthetic regulation and energy balance (Munekage et al., 2002, 2004; Joliot and Johnson, 2011; Kramer and Evans, 2011; Walker et al., 2014, 2016), its photoinhibition has a serious impact on the rate of $\mathrm{CO}_{2}$ assimilation and, thus,
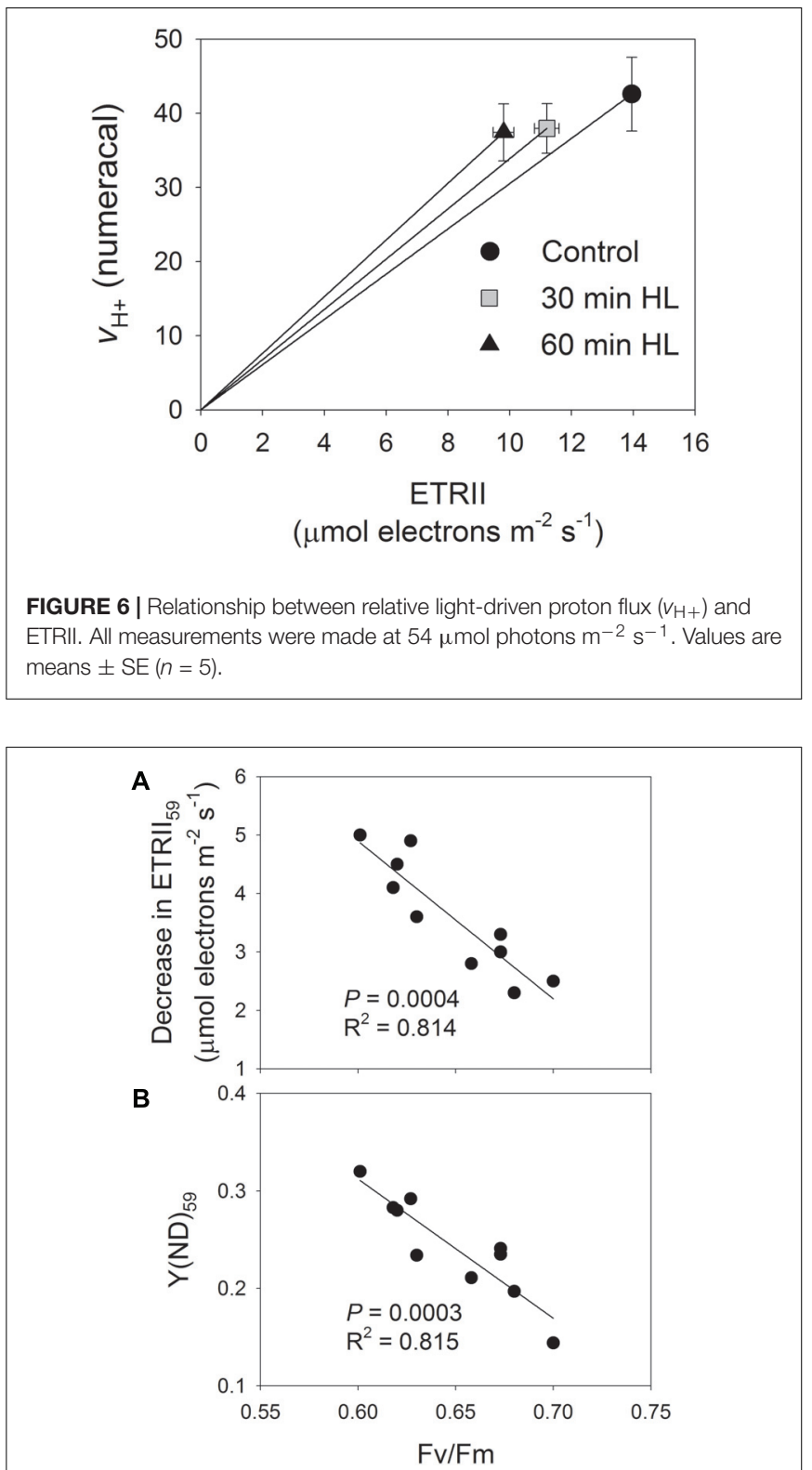

FIGURE 7 | (A) Relationship between $F_{\mathrm{V}} / F_{\mathrm{m}}$ and decrease in ETR $\|_{59}$, and (B) relationship between $F_{\mathrm{V}} / F_{\mathrm{m}}$ and $Y(N D)_{59}$. Decrease in ETRI ${ }_{59}$ represents reduction in ETRII at $59 \mu \mathrm{mol}$ photons $\mathrm{m}^{-2} \mathrm{~s}^{-1}$ after high-light treatments; $Y(N D)_{59}$ is value for $Y(N D)$ measured at $59 \mu \mathrm{mol}$ photons $\mathrm{m}^{-2} \mathrm{~s}^{-1}$ after treatments.

LEF (Zivcak et al., 2015; Yamori et al., 2016). We also note that both of those studies involved detached leaves, which would affect stomatal conductance. As a result, PSI photoinhibition and the use of detached leaves would have presented important interactive factors that influenced LEF. In the present study, we excluded the effect of PSI photoinhibition by testing attached leaves, which also allowed us to avoid seeing a decrease in stomatal conductance during our treatments.

In detached leaves of Capsicum annuum, the light-saturated rates of oxygen evolution do not decrease when PSII activity 
declines by $40 \%$ (Lee et al., 1999). Accordingly, Lee et al. (1999) have assumed that PSII complexes occur in excess of the number needed to sustain light-saturated LEF by about $40 \%$. We found here that PSII activity decreased by only $17 \%$, which led to a significant reduction in LEF under all light intensities. Moreover, the experiments described by Lee et al. (1999) involved leaf disks for the photoinhibitory treatments and photosynthetic measurements, and the light-saturated rate of oxygen evolution could have been restricted by the in vitro state. Therefore, to overcome the influence of the in vitro state on stomatal conductance and LEF, we used attached leaves for all measurements. We were interested to learn that the extent of PSII photoinhibition was significantly correlated with the decrease in ETRII at $59 \mu \mathrm{mol}$ photons $\mathrm{m}^{-2} \mathrm{~s}^{-1}$ after the highlight treatments. This indicated that the rate of LEF under low light is strongly determined by residual PSII activity. Therefore, PSII complexes may not occur in excess of the number needed to sustain maximum LEF in the shade-adapted $P$. notoginseng.

Shade-demanding plants usually grow slowly or die under high light (Krause et al., 2012). However, the underlying photosynthetic mechanisms are not clear. Species such as $P$. notoginseng are sensitive to high-light stress (Chen et al., 2016) and we found here that moderate PSII photoinhibition significantly depressed LEF under all light levels. Accordingly, after exposure to prolonged high-light stress, the rate of $\mathrm{CO}_{2}$ assimilation would be expected to show a large decrease due to severe PSII photoinhibition. When the carbon gain via photosynthetic $\mathrm{CO}_{2}$ assimilation cannot satisfy carbon consumption for respiration, plant growth ceases. Therefore, our present results provide new insight into the effect of high light on the growth of shade-demanding plants.

\section{PSII Photoinhibition Modifies PSI Redox State Under Low Light}

The value calculated for $Y(\mathrm{ND})$ under a low intensity of $59 \mu$ mol photons $\mathrm{m}^{-2} \mathrm{~s}^{-1}$ increased significantly after highlight treatments, and $Y(\mathrm{ND})$ was negatively correlated with $F_{\mathrm{V}} / F_{\mathrm{m}}$. That is, PSII photoinhibition led to a significant increase in the P700 oxidation ratio. The value for $Y(\mathrm{ND})$ depends upon two factors: (1) electron flow from PSII to PSI (Tikkanen et al., 2014; Huang et al., 2016b), and (2) the buildup of proton motive force (Munekage et al., 2002, 2004; Kanazawa et al., 2017; Takagi et al., 2017). When PSII activity is

\section{REFERENCES}

Allakhverdiev, S. I., Kreslavski, V. D., Klimov, V. V., Los, D. A., Carpentier, R., and Mohanty, P. (2008). Heat stress: an overview of molecular responses in photosynthesis. Photosynth. Res. 98, 541-550. doi: 10.1007/s11120-0089331-0

Allakhverdiev, S. I., Los, D. A., Mohanty, P., Nishiyama, Y., and Murata, N. (2007). Glycinebetaine alleviates the inhibitory effect of moderate heat stress on the repair of photosystem II during photoinhibition. Biochim. Biophys. Acta 1767, 1363-1371. doi: 10.1016/j.bbabio.2007.10.005

Allakhverdiev, S. I., Mohanty, P., and Murata, N. (2003). Dissection of photodamage at low temperature and repair in darkness suggests the existence of an intermediate form of photodamaged photosystem II. Biochemistry 42, 14277-14283. doi: 10.1021/bi035205+ severely photo-damaged (i.e., PSII functioning is reduced to $40 \%$ of the control value), then $Y(\mathrm{ND})$ under both low- and highlight intensities largely increases in pgr5 plants of A. thaliana (Tikkanen et al., 2014). In A. thaliana mutants that have higher ATP synthase activity, the greater proton efflux from thylakoid lumen to stroma leads to a loss of lumenal acidification, causing a decline in $Y(\mathrm{ND})$ and, thus, PSI photoinhibition (Kanazawa et al., 2017; Takagi et al., 2017). Although our study showed that $Y(\mathrm{ND})$ increased at $59 \mu \mathrm{mol}$ photons $\mathrm{m}^{-2} \mathrm{~s}^{-1}$, that response was not accompanied by a rise in $\Delta \mathrm{pH}$. We propose, therefore, that the increase in $Y(\mathrm{ND})$ was mainly caused by depressed electron flow from PSII.

\section{CONCLUSION}

We examined the effect of selective PSII photoinhibition on LEF in attached leaves of a shade-demanding species, $P$. notoginseng. Moderate PSII photoinhibition significantly depressed LEF under all light intensities. However, because PSI photoinhibition did not occur and lumenal acidification did not increase after highlight treatments, we suggest that this decrease in LEF was mainly caused by a significant decline in PSII activity. Therefore, this species might not have an adequate number of PSII complexes to sustain maximum LEF. These findings provide a new perspective on how intense illumination influences the growth of shadeadapted plants.

\section{AUTHOR CONTRIBUTIONS}

$\mathrm{WH}, \mathrm{S}-\mathrm{BZ}$, and TL conceived and designed research and analyzed the data. WH conducted experiments and wrote the first draft of the manuscript, which was intensively edited by S-BZ and TL.

\section{FUNDING}

This study was supported by the National Natural Science Foundation of China (31670343, 31560085, and 81473310), the Youth Innovation Promotion Association of the Chinese Academy of Sciences (to WH, 2016347), and the Major Science and Technique Programs in Yunnan Province (2016ZF001).

Allakhverdiev, S. I., and Murata, N. (2004). Environmental stress inhibits the synthesis de novo of proteins involved in the photodamage-repair cycle of photosystem II in Synechocystis sp. PCC 6803. Biochim. Biophys. Acta 1657, 23-32. doi: 10.1016/j.bbabio.2004.03.003

Allakhverdiev, S. I., Nishiyama, Y., Takahashi, S., Miyairi, S., Suzuki, I., and Murata, N. (2005). Systematic analysis of the relation of electron transport and ATP synthesis to the photodamage and repair of photosystem II in Synechocystis. Plant Physiol. 137, 263-273. doi: 10.1104/pp.104.054478

Aro, E. M., Virgin, I., and Andersson, B. (1993a). Photoinhibition of photosystem II. Inactivation, protein damage and turnover. Biochim. Biophys. Acta 1143, 113-134. doi: 10.1016/0005-2728(93)90134-2

Aro, E. M., McCaffery, S., and Anderson, J. (1993b). Photoinhibition and D1 protein degradation in peas acclimated to different growth irradiances. Plant Physiol. 103, 835-843. doi: 10.1104/pp.103.3.835 
Barber, J., and Andersson, B. (1992). Too much of a good thing: light can be bad for photosynthesis. Trends Biochem. Sci. 17, 61-66. doi: 10.1016/0968-0004(92) 90503-2

Barth, C., Krause, G. H., and Winter, K. (2001). Responses of photosystem I compared with photosystem II to high-light stress in tropical shade and sun leaves. Plant Cell Environ. 24, 163-176. doi: 10.1111/j.1365-3040.2001.00673.x

Brestic, M., Cornic, G., Fryer, M. J., and Baker, N. R. (1995). Does photorespiration protect the photosynthetic apparatus in French bean leaves from photoinhibition during drought stress? Planta 196, 450-457. doi: 10.1007/ BF00203643

Brestic, M., Zivcak, M., Kalaji, H. M., Carpentier, R., and Allakhverdiev, S. I. (2012). Photosystem II thermostability in situ: environmentally induced acclimation and genotype-specific reactions in Triticum aestivum L. Plant Physiol. Biochem. 57, 93-105. doi: 10.1016/j.plaphy.2012.05.012

Brestic, M., Zivcak, M., Kunderlikova, K., Sytar, O., Shao, H., Kalaji, H. M., et al. (2015). Low PSI content limits the photoprotection of PSI and PSII in early growth stages of chlorophyll b-deficient wheat mutant lines. Photosynth. Res. 125, 151-166. doi: 10.1007/s11120-015-0093-1

Chen, J. W., Kuang, S. B., Long, G. Q., Yang, S. C., Meng, Z. G., Li, L. G., et al. (2016). Photosynthesis, light energy partitioning, and photoprotection in the shade-demanding species Panax notoginseng under high and low level of growth irradiance. Funct. Plant Biol. 43, 479-491. doi: 10.1071/FP15283

Cruz, J. A., Avenson, T. J., Kanazawa, A., Takizawa, K., Edwards, G. E., and Kramer, D. M. (2005). Plasticity in light reactions of photosynthesis for energy production and photoprotection. J. Exp. Bot. 56, 395-406. doi: 10.1093/jxb/ eri022

Genty, B., Briantais, J. M., and Baker, N. R. (1989). The relationship between the quantum yield of photosynthetic electron transport and quenching of chlorophyll fluorescence. Biochim. Biophys. Acta 990, 87-92. doi: 10.1016/ S0304-4165(89)80016-9

Hakala, M., Tuominen, I., Keranen, M., Tyystjarvi, T., and Tyystjarvi, E. (2005). Evidence for the role of the oxygen-evolving manganese complex in photoinhibition of photosystem II. Biochim. Biophys. Acta 1706, 68-80. doi: 10.1016/j.bbabio.2004.09.001

Hikosaka, K., Kato, M. C., and Hirose, T. (2004). Photosynthetic rates and partitioning of absorbed light energy in photoinhibited leaves. Physiol. Plant. 121, 699-708. doi: 10.1111/j.1399-3054.2004.00364.x

Hirotsu, N., Makino, A., Yokota, S., and Mae, T. (2005). The photosynthetic properties of rice leaves treated with low temperature and high irradiance. Plant Cell Physiol. 46, 1377-1383. doi: 10.1093/pcp/pci149

Hope, A. B., Valente, P., and Matthews, D. B. (1994). Effects of $\mathrm{pH}$ on the kinetics of redox reactions in and around the cytochrome bf complex in an isolated system. Photosynth. Res. 42, 111-120. doi: 10.1007/BF02187122

Huang, W., Tikkanen, M., and Zhang, S. B. (2018). Photoinhibition of photosystem I in Nephrolepis falciformis depends on reactive oxygen species generated in the chloroplast stroma. Photosynth. Res. doi: 10.1007/s11120-018-0484-1 [Epub ahead of print].

Huang, W., Yang, S. J., Zhang, S. B., Zhang, J. L., and Cao, K. F. (2012). Cyclic electron flow plays an important role in photoprotection for the resurrection plant Paraboea rufescens under drought stress. Planta 235, 819-828. doi: 10.1007/s00425-011-1544-3

Huang, W., Yang, Y. J., Hu, H., Cao, K. F., and Zhang, S. B. (2016a). Sustained diurnal stimulation of cyclic electron flow in two tropical tree species Erythrophleum guineense and Khaya ivorensis. Front. Plant Sci. 7:1068. doi: 10.3389/fpls.2016.01068

Huang, W., Yang, Y. J., Hu, H., and Zhang, S. B. (2016b). Moderate photoinhibition of photosystem II protects photosystem I from photodamage at chilling stress in tobacco leaves. Front. Plant Sci. 7:182. doi: 10.3389/fpls.2016.00182

Huang, W., Yang, Y. J., Hu, H., and Zhang, S. B. (2016c). Responses of photosystem I compared with photosystem II to fluctuating light in the shade-establishing tropical tree species Psychotria henryi. Front. Plant Sci. 7:1549. doi: 10.3389/ fpls.2016.01549

Huang, W., Yang, Y. J., Zhang, J. L., Hu, H., and Zhang, S. B. (2016d). PSI photoinhibition is more related to electron transfer from PSII to PSI rather than PSI redox state in Psychotria rubra. Photosynth. Res. 129, 85-92. doi: 10.1007/s11120-016-0275-5

Huang, W., Yang, Y. J., Zhang, J. L., Hu, H., and Zhang, S. B. (2017). Superoxide generated in the chloroplast stroma causes photoinhibition of photosystem I in the shade-establishing tree species Psychotria henryi. Photosynth. Res. 132, 293-303. doi: 10.1007/s11120-017-0389-4

Huang, W., Zhang, S. B., and Cao, K. F. (2010). Stimulation of cyclic electron flow during recovery after chilling-induced photoinhibition of PSII. Plant Cell Physiol. 51, 1922-1928. doi: 10.1093/pcp/pcq144

Huang, W., Zhang, S. B., Zhang, J. L., and Hu, H. (2015). Photoinhibition of photosystem I under high light in the shade-established tropical tree species Psychotria rubra. Front. Plant Sci. 6:801. doi: 10.3389/fpls.2015.00801

Johnson, M. P., and Ruban, A. V. (2010). Arabidopsis plants lacking PsbS protein possess photoprotective energy dissipation. Plant J. 61, 283-289. doi: 10.1111/j. 1365-313X.2009.04051.x

Joliot, P., and Johnson, G. N. (2011). Regulation of cyclic and linear electron flow in higher plants. Proc. Natl. Acad. Sci. U.S.A. 108, 13317-13322. doi: 10.1073/ pnas. 1110189108

Kanazawa, A., Ostendorf, E., Kohzuma, K., Hoh, D., Strand, D. D., SatoCruz, M., et al. (2017). Chloroplast ATP synthase modulation of the thylakoid proton motive force: implications for photosystem I and photosystem II photoprotection. Front. Plant Sci. 8:719. doi: 10.3389/fpls.2017. 00719

Kitao, M., Lei, T. T., Koike, T., Tobita, H., and Muruyama, Y. (2000). Susceptibility to photoinhibition of three deciduous broadleaf tree species with different successional traits raised under various light regimes. Plant Cell Environ. 23, 81-89. doi: 10.1046/j.1365-3040.2000.00528.x

Klughammer, C., and Schreiber, U. (2008). Saturation pulse method for assessment of energy conversion in PSI. PAM Appl. Notes 1, 11-14.

Kornyeyev, D., Logan, B. A., Tissue, D. T., Allen, R. D., and Holaday, A. S. (2006). Compensation for PSII photoinactivation by regulated non-photochemical dissipation influences the impact of photoinactivation on electron transport and $\mathrm{CO}_{2}$ assimilation. Plant Cell Physiol. 47, 437-446. doi: 10.1093/pcp/pcj010

Kramer, D. M., and Evans, J. R. (2011). The importance of energy balance in improving photosynthetic productivity. Plant Physiol. 155, 70-78. doi: 10.1104/ pp.110.166652

Krause, G. H., Grube, E., Koroleva, O. Y., Barth, C., and Winter, K. (2004). Do mature shade leaves of tropical tree seedlings acclimate to high sunlight and UV radiation? Funct. Plant Biol. 31, 743-756. doi: 10.1071/FP03239

Krause, G. H., Winter, K., Matsubara, S., Krause, B., Jahns, P., Virgo, A., et al. (2012). Photosynthesis, photoprotection, and growth of shade-tolerant tropical tree seedlings under full sunlight. Photosynth. Res. 113, 273-285. doi: 10.1007/ s11120-012-9731-z

Kulheim, C., Agren, J., and Jansson, S. (2002). Rapid regulation of light harvesting and plant fitness in the field. Science 297, 91-93. doi: 10.1126/science.1072359

Lee, H. Y., Chow, W. S., and Hong, Y. N. (1999). Photoinactivation of photosystem II in leaves of Capsicum annuum. Physiol. Plant. 105, 376-383. doi: 10.1034/j. 1399-3054.1999.105224.x

Lin, Z., Peng, C., Sun, Z., and Lin, G. (2000). Effect of light intensity on partitioning of photosynthetic electron transport to photorespiration in four subtropical forest plants. Sci. China C Life Sci. 43, 347-354. doi: 10.1007/BF02879298

Livingston, A. K., Cruz, J. A., Kohzuma, K., Dhingra, A., and Kramer, D. M. (2010). An Arabidopsis mutant with high cyclic electron flow around photosystem I (hcef) involving the NDH complex. Plant Cell 22, 221-233. doi: 10.1105/tpc. 109.071084

Munekage, Y., Hashimoto, M., Miyake, C., Tomizawa, K. I., Endo, T., Tasaka, M., et al. (2004). Cyclic electron flow around photosystem I is essential for photosynthesis. Nature 429, 579-582. doi: 10.1038/nature02598

Munekage, Y., Hojo, M., Meurer, J., Endo, T., Tasaka, M., and Shikanai, T. (2002). PGR5 is involved in cyclic electron flow around photosystem I and is essential for photoprotection in Arabidopsis. Cell 110, 361-371. doi: 10.1016/S00928674(02)00867-X

Murata, N., Allakhverdiev, S. I., and Nishiyama, Y. (2012). The mechanism of photoinhibition in vivo: re-evaluation of the roles of catalase, $\alpha$-tocopherol, non-photochemical quenching, and electron transport. Biochim. Biophys. Acta 1817, 1127-1133. doi: 10.1016/j.bbabio.2012.02.020

Murata, N., Takahashi, S., Nishiyama, Y., and Allakhverdiev, S. I. (2007). Photoinhibition of photosystem II under environmental stress. Biochim. Biophys. Acta 1767, 414-421. doi: 10.1016/j.bbabio.2006.11.019

Murchie, E. H., and Niyogi, K. K. (2011). Manipulation of photoprotection to improve plant photosynthesis. Plant Physiol. 155, 86-92. doi: 10.1104/pp.110. 168831 
Nishio, J. N., and Whitmarsh, J. (1993). Dissipation of the proton electrochemical potential in intact chloroplasts (II. The $\mathrm{pH}$ gradient monitored by cytochrome f reduction kinetics). Plant Physiol. 101, 89-96. doi: 10.1104/pp.101.1.89

Nishiyama, Y., Allakhverdiev, S. I., and Murata, N. (2006). A new paradigm for the action of reactive oxygen species in the photoinhibition of photosystem II. Biochim. Biophys. Acta 1757, 742-749. doi: 10.1016/j.bbabio.2006.05.013

Nishiyama, Y., Allakhverdiev, S. I., Yamamoto, H., Hayashi, H., and Murata, N. (2004). Singlet oxygen inhibits the repair of photosystem II by suppressing the translation elongation of the D1 protein in Synechocystis sp. PCC 6803. Biochemistry 43, 11321-11330. doi: 10.1021/bi036178q

Nishiyama, Y., Yamamoto, H., Allakhverdiev, S. I., Inaba, M., Yokota, A., and Murata, N. (2001). Oxidative stress inhibits the repair of photodamage to the photosynthetic machinery. EMBO J. 20, 5587-5594. doi: 10.1093/emboj/20.20. 5587

Ogren, F., and Sjostrom, M. (1990). Estimation of the effect of photoinhibition on the carbon gain in leaves of a willow canopy. Planta 181, 560-567. doi: 10.1007/BF00193011

Ohnishi, N., Allakhverdiev, S. I., Takahashi, S., Higashi, S., Watanabe, M., Nishiyama, Y., et al. (2005). Two-step mechanism of photodamage to photosystem II: step one occurs at the oxygen-evolving complex and step two occurs at the photochemical reaction center. Biochemistry 44, 8494-8499. doi: 10.1021/bi047518q

Oxborough, K., and Baker, N. R. (1997). Resolving chlorophyll a fluorescence images of photosynthetic efficiency into photochemical and nonphotochemical components - Calculation of $\mathrm{qP}$ and $F v^{\prime} / F m^{\prime}$ without measuring Fo'. Photosynth. Res. 54, 135-142. doi: 10.1023/A:1005936823310

Powles, S. B. (1984). Photoinhibition of photosynthesis induced by visible light. Annu. Rev. Plant Physiol. 35, 15-44. doi: 10.1146/annurev.pp.35.060184.000311

Sacksteder, C. A., Jacoby, M. E., and Kramer, D. M. (2001). A portable, nonfocusing optics spectrometer (NoFOSpec) for measurements of steady-state absorbance changes in intact plants. Photosynth. Res. 70, 231-240. doi: 10.1023/ A: 1017906626288

Sacksteder, C. A., and Kramer, D. M. (2000). Dark interval relaxation kinetics of absorbance changes as a quantitative probe of steady-state electron transfer. Photosynth. Res. 66, 145-158. doi: 10.1023/A:1010785912271

Shikanai, T. (2014). Central role of cyclic electron transport around photosystem I in the regulation of photosynthesis. Curr. Opin. Biotechnol. 26, 25-30. doi: 10.1016/j.copbio.2013.08.012

Shikanai, T. (2016). Regulatory network of proton motive force: contribution of cyclic electron transport around photosystem I. Photosynth. Res. 129, 253-260. doi: 10.1007/s11120-016-0227-0

Suorsa, M., Jarvi, S., Grieco, M., Nurmi, M., Pietrzykowska, M., Rantala, M., et al. (2012). PROTON GRADIENT REGULATION5 is essential for proper acclimation of Arabidopsis photosystem I to naturally and artificially fluctuating light conditions. Plant Cell 24, 2934-2948. doi: 10.1105/tpc.112.097162

Suorsa, M., Rossi, F., Tadini, L., Labs, M., Colombo, M., Jahns, P., et al. (2016). PGR5-PGRL1-dependent cyclic electron transport modulates linear electron transport rate in Arabidopsis thaliana. Mol. Plant 9, 271-288. doi: 10.1016/j. molp.2015.12.001
Takagi, D., Amako, K., Hashiguchi, M., Fukaki, H., Ishizaki, K., Goh, T., et al. (2017). Chloroplastic ATP synthase builds up proton motive force for preventing reactive oxygen species production in photosystem I. Plant J. 91, 306-324. doi: 10.1111/tpj.13566

Takahashi, S., Bauwe, H., and Badger, M. R. (2007). Impairment of the photorespiratory pathway accelerates photoinhibition of photosystem II by suppression of repair but not acceleration of damage processes in Arabidopsis. Plant Physiol. 144, 487-494. doi: 10.1104/pp.107.097253

Takahashi, S., Milward, S. E., Fan, D. Y., Chow, W. S., and Badger, M. R. (2009). How does cyclic electron flow alleviate photoinhibition in Arabidopsis? Plant Physiol. 149, 1560-1567. doi: 10.1104/pp.108.134122

Takizawa, K., Cruz, J. A., Kanazawa, A., and Kramer, D. M. (2007). The thylakoid proton motive force in vivo. Quantitative, non-invasive probes, energetics, and regulatory consequences of light-induced pmf. Biochim. Biophys. Acta 1767, 1233-1244. doi: 10.1016/j.bbabio.2007.07.006

Takizawa, K., Kanazawa, A., and Kramer, D. M. (2008). Depletion of stromal Pi induces high 'energy-dependent' antenna exciton quenching $(\mathrm{qE})$ by decreasing proton conductivity at $\mathrm{CF}_{\mathrm{o}}-\mathrm{CF}_{1}$ ATP synthase. Plant Cell Environ. 31, 235-243. doi: 10.1111/j.1365-3040.2007.01753.x

Tikkanen, M., and Aro, E. M. (2014). Integrative regulatory network of plant thylakoid energy transduction. Trends Plant Sci. 19, 10-17. doi: 10.1016/j. tplants.2013.09.003

Tikkanen, M., Mekala, N. R., and Aro, E. M. (2014). Photosystem II photoinhibition-repair cycle protects Photosystem I from irreversible damage. Biochim. Biophys. Acta 1837, 210-215. doi: 10.1016/j.bbabio.2013.10.001

Walker, B. J., Strand, D. D., Kramer, D. M., and Cousins, A. B. (2014). The response of cyclic electron flow around photosystem I to changes in photorespiration and nitrate assimilation. Plant Physiol. 165, 453-462. doi: 10.1104/pp.114.238238

Walker, B. J., VanLoocke, A., Bernacchi, C. J., and Ort, D. R. (2016). The costs of photorespiration to food production now and in the future. Annu. Rev. Plant Biol. 67, 107-129. doi: 10.1146/annurev-arplant-043015-111709

Yamori, W., Makino, A., and Shikanai, T. (2016). A physiological role of cyclic electron transport around photosystem I in sustaining photosynthesis under fluctuating light in rice. Sci. Rep. 6:20147. doi: 10.1038/srep20147

Zivcak, M., Brestic, M., Kunderlikova, K., Sytar, O., and Allakhverdiev, S. I. (2015). Repetitive light pulse-induced photoinhibition of photosystem I severely affects $\mathrm{CO}_{2}$ assimilation and photoprotection in wheat leaves. Photosynth. Res. 126, 449-463. doi: 10.1007/s11120-015-0121-1

Conflict of Interest Statement: The authors declare that the research was conducted in the absence of any commercial or financial relationships that could be construed as a potential conflict of interest.

Copyright (c) 2018 Huang, Zhang and Liu. This is an open-access article distributed under the terms of the Creative Commons Attribution License (CC BY). The use, distribution or reproduction in other forums is permitted, provided the original author(s) and the copyright owner are credited and that the original publication in this journal is cited, in accordance with accepted academic practice. No use, distribution or reproduction is permitted which does not comply with these terms. 